\title{
Physiology and morphology of Legionella pneumophila in continuous culture at low oxygen concentration
}

\author{
W. Stuart Mauchline, ${ }^{*}$ Rosa Araujo, $†$ Robin Wait, A. Barry Dowsett, P. Julian Dennis $\ddagger$ \\ and C. William KeEVIL \\ Pathology Division, PHLS Centre for Applied Microbiology \& Research, Porton Down, Salisbury, Wilts. SP4 0JG, UK
}

(Received 22 May 1992; revised 17 July 1992; accepted 13 August 1992)

\begin{abstract}
Two strains of Legionella pneumophila serogroup 1 monoclonal subgroup Pontiac were grown for the first time in continuous culture using a chemically defined medium. The influence of temperature on physiology and morphology was investigated by fixing the growth rate (equal to the dilution rate, $D$ ) at $0.08 \mathrm{~h}^{-1}$ and controlling the pH and dissolved oxygen concentration of the culture. Serine provided the principal source of carbon and energy but growth was limited by tyrosine. The bacterium behaved as a microaerophile in this medium, with maximal growth occurring at $0 \cdot 31\left(\mathrm{mg} \mathrm{O}_{2}\right) \mathrm{I}^{-1}$ (equivalent to a dissolved oxygen tension of $4 \%(\mathrm{v} / \mathrm{v})$ air saturation at $30{ }^{\circ} \mathrm{C}$ ). The cultures consisted of flagellated, short rods at $24^{\circ} \mathrm{C}$, but exhibited an increased level of pleomorphism and the loss of flagella as the temperature was increased to $37^{\circ} \mathrm{C}$. The presence of intracellular granules was noted, and their abundance was temperature-dependent. Polyhydroxybutyrate was present in $L$. pneumophila, and the proportion of the cell dry weight that it accounted for varied with temperature, being maximal at $24^{\circ} \mathrm{C}$. The ratio of saturated to unsaturated fatty acids in the cells decreased as the temperature was reduced towards $24{ }^{\circ} \mathrm{C}, \mathrm{so}$ as to maintain membrane fluidity at low growth temperature.
\end{abstract}

\section{Introduction}

The principal aetiological agent of Legionnaires' disease, Legionella pneumophila, has been isolated from a wide range of habitats, including natural surface waters (Fliermans et al., 1981) and man-made systems (Dennis et al., 1982; Bartlett et al., 1983), which vary both physically and chemically. Thermotolerance is one of the most interesting characteristics of legionellae: Wadowsky et al. (1986) demonstrated that naturally occurring $L$. pneumophila could multiply between 25 and $37^{\circ} \mathrm{C}$; Dennis et al. (1984) showed that there was no significant loss of viability at $46^{\circ} \mathrm{C}$; and Fliermans et al. (1981) isolated $L$. pneumophila from natural surface waters between 5.7 and $63^{\circ} \mathrm{C}$. Man-made water systems such as cooling towers, hot water systems and whirlpool spas can act as amplifiers of legionellae numbers and as

* Author for correspondence. Tel. (0980) 610391 ext. 2390; fax (0980) 611096.

$\dagger$ Present address: Departamento de Microbiologia, Universidad de Barcelona, Av. Diagonal 645, Barcelona 08071, Spain.

$\ddagger$ Present address: Spencer Harris Laboratory, Thames Water Utilities, Manor Farm Road, Reading RG2 0JN, UK. generators of respirable aerosols, and have thus been the main sources of both cases and outbreaks of legionellosis.

In such systems, the growth of bacteria is probably sub-optimal due to the low availability of nutrients. It is not possible to sustain growth in batch culture under such conditions; in continuous culture however, it is possible to maintain steady-state growth at almost any growth rate for as long as is required. In addition to providing a constant chemical environment, chemostat culture allows the growth rate to be fixed whilst environmental parameters are changed (Monod, 1950; Novick \& Szilard, 1950; Herbert et al., 1956). For these reasons the chemostat was chosen as the most appropriate tool for investigating the influence of environment on $L$. pneumophila.

Early studies suggested that legionellae were fastidious and required amino acids, especially L-cysteine (George et al., 1980; Tesh \& Miller, 1981; Ristroph et al., 1981), and iron, possibly in the ferric form (Feeley et al., 1978). In the environment legionellae may obtain essential nutrients via associations with amoebae (Rowbotham, 1980 ) or with other micro-organisms in biofilms (Keevil et al., 1988). Legionellae are unusual among Gramnegative bacteria in that their principal sources of 
carbon and energy are amino acids; glucose and polysaccharides being used very poorly (Hoffman, 1984).

Previous studies have shown that $L$. pneumophila can be grown in continuous culture, but only using complex media (Berg et al., 1985; Dennis, 1986). Such media do not reflect the conditions experienced by legionellae in the environment, either in water systems or in vivo. Moreover, complex media are inappropriate for physiological studies since it is not only difficult to determine the limiting nutrient but also almost impossible to define the available concentrations of nutrients such as amino acids and vitamins. Accordingly, we have used the defined medium of Pine et al. (1986) which has proved suitable for the growth of legionellae in batch culture. This present study describes the influence that temperatures which are normally encountered in vitro and in vivo have on the physiology and morphology of two strains of $L$. pneumophila serogroup 1 monoclonal subgroup Pontiac.

\section{Methods}

Strain and culture. The chemostat was inoculated with either the environmental strain $74 / 81$ or the clinical isolate Corby. The strains used were stored as individual aliquots at $-80^{\circ} \mathrm{C}$, and were grown on Buffered Charcoal Yeast Extract (BCYE) agar (Edelstein, 1981) for $72 \mathrm{~h}$ at $37^{\circ} \mathrm{C}$ prior to inoculation of the chemostat. The one litre chemostat vessel contained $500 \mathrm{ml}$ ACES-buffered chemically defined medium (ABCD; Pine et al., 1986). The culture medium was initially purged with oxygen-free nitrogen (BOC) and maintained at an oxygen concentration of $0.31 \mathrm{mg} \mathrm{l}^{-1}$ [equivalent to $4 \%(\mathrm{v} / \mathrm{v})$ of air saturation at $30{ }^{\circ} \mathrm{C}$ ] through feedback control of the agitation rate, by an Anglicon Microlab Fermentation Control System (Brighton Systems, Newhaven, UK) linked to a galvanic oxygen electrode (Uniprobe, Cardiff). Temperature and $\mathrm{pH}$ were controlled using appropriate Anglicon Microlab controllers linked to an Anglicon temperature probe (which also provided a signal for temperature compensation of the $\mathrm{pH}$ controller) and an Ingold $\mathrm{pH}$ electrode (Mettler-Toledo, Leicester, $\mathrm{UK})$. The $\mathrm{pH}$ was controlled to 6.9 by the addition of potassium hydroxide (1 $\mathrm{M})$. After inoculation the culture was grown in batch until the $\mathrm{OD}_{540}$ reached $0 \cdot 4$. Continuous culture was initiated at a dilution rate $(D)$ of $0.03 \mathrm{~h}^{-1}$, and then increased to $0.08 \mathrm{~h}^{-1}$ (equivalent to a mean generation time (MGT) of $8.7 \mathrm{~h}$ ) when the $\mathrm{OD}_{540}$ had increased to approximately $1 \cdot 0 . \mathrm{OD}_{540}$ and cell dry weight were used to assess when the steady state had been achieved.

Electron microscopy. Cells obtained from the chemostat were left in $0.2 \%$ formaldehyde for $2 \mathrm{~h}$, applied to formvar/carbon filmed, 400 mesh copper EM specimen grids, and negatively stained with $1 \%(\mathrm{w} / \mathrm{v})$ sodium silicotungstate. Alternatively, cells were fixed in $2.5 \%(\mathrm{v} / \mathrm{v})$ glutaraldehyde and $1 \%(\mathrm{w} / \mathrm{v})$ osmium tetroxide for embedding, thin sectioning and staining by the silver proteinate method of Thierry (1967). Specimens were examined in a Philips EM 400T transmission electron microscope operated at $80 \mathrm{kV}$.

Culture analyses. The optical density and biomass concentration of the cultures were monitored as described previously (Keevil et al., 1988). Ammonia, amino acids and cations in the uninoculated medium and the clarified supernatants were analysed by the methods of Ellwood et al. (1974). Total viable counts were determined by plating on to BCYE agar and incubating at $37^{\circ} \mathrm{C}$.
Cell analyses. The presence of intracellular lipid granules was confirmed using Sudan Black stain (Burdon, 1946). Polyhydroxybutyrate (PHB) was extracted from washed cells by a modification of the method of Findlay \& White (1983). Briefly, 0.5 g lyophilized cells were placed in a cellulose thimble (Whatman) and extracted with chloroform for several hours in a Soxhlet apparatus. After cooling, the extract was transferred to a $100 \mathrm{ml}$ flask and the chloroform removed by rotary evaporation. The PHB was purified by washing 4 times with $3 \mathrm{ml}$ portions of ice cold ethanol, until the washings were colourless. This procedure was repeated with four $3 \mathrm{ml}$ portions of cold diethyl ether, and the residue was dried by rotary evaporation, producing a white membrane-like solid. The material was dissolved in $25 \mathrm{ml}$ chloroform and the PHB concentration in $20 \mu \mathrm{l}$ aliquots was determined by a modification of the method of Slepecky \& Law (1960), as follows: $5 \mathrm{ml}$ concentrated sulphuric acid was added to the dry PHB in a screw cap tube and after thorough mixing the tubes were heated at $100{ }^{\circ} \mathrm{C}$ for $30 \mathrm{~min}$. This procedure dehydrated the PHB to crotonic acid, the UV absorption of which was determined at $235 \mathrm{~nm}$ in silica cuvettes using a SP1800 spectrophotometer (Pye Unicam). A standard curve was constructed using PHB purified from Alcaligenes sp. (Sigma); determinations were done in triplicate and the standard deviation was never more than $3 \%$ of the mean.

Fatty acid and polar lipid extraction. Cellular fatty acid samples were prepared as described by Wait (1988). Briefly, freeze-dried cells were incubated overnight at $60^{\circ} \mathrm{C}$ with $2 \mathrm{ml}$ toluene/methanol $(1: 1, \mathrm{v} / \mathrm{v})$, containing $50 \mu \mathrm{l}$ concentrated sulphuric acid, in a $5 \mathrm{ml}$ screw-capped tube. The tubes were cooled, $1 \mathrm{ml}$ of saturated salt solution was added, and the fatty acids extracted into hexane/chloroform $(4: 1, \mathrm{v} / \mathrm{v})$. The extracts were dried in a stream of nitrogen, and redissolved in $1 \mathrm{ml}$ trimethylpentane for gas chromatography.

Phospholipids were extracted by a modification of the procedure of Bligh \& Dyer (1959). Approximately $2 \mathrm{mg}$ freeze-dried biomass was shaken with $1 \mathrm{ml}$ of a monophasic mixture of chloroform, methanol and water $(1: 2: 0 \cdot 8$, by vol.). Additional water and chloroform $(0 \cdot 3 \mathrm{ml}$ of each) were then added so as to force a phase separation. The organic layer containing the phospholipids was removed, washed with water, concentrated under nitrogen, and redissolved in $100 \mu \mathrm{l}$ chloroform/ methanol prior to analysis by positive and negative fast atom bombardment (FAB) mass-spectrometry.

The position of fatty acid substituents in the phospholipids were determined by digestion with phospholipase $\mathrm{A}_{2}$. The samples were dissolved in $3 \mathrm{ml}$ diethyl ether/methanol $(98: 2, \mathrm{v} / \mathrm{v})$, and 10 units Crotalus atrox phospholipase $\mathrm{A}_{2}$ (Sigma, product number P-3770) in $0.5 \mathrm{ml}$ borate buffer ( $\mathrm{pH} \mathrm{8.9)}$ were added. After incubation overnight at $37^{\circ} \mathrm{C}$ with constant shaking, the digestion products were recovered by Bligh-Dyer extraction and analysed by FAB-MS

Gas chromatography and mass spectrometry. Gas chromatography was performed with a Carlo-Erba 4130 chromatograph fitted with a $25 \mathrm{~m} \times 0.2 \mathrm{~mm}$ fused silica column, coated with BP-5 (SGE) using helium as carrier gas at a linear velocity of $30 \mathrm{~cm} \mathrm{~s}^{-1}$. The samples were introduced by splitless injection (splitless time $30 \mathrm{~s}$ ) at an initial oven temperature of $80^{\circ} \mathrm{C}$. After a one minute delay, the oven temperature was programmed at $4{ }^{\circ} \mathrm{C} \mathrm{min}-1$ to $205^{\circ} \mathrm{C}$, and this temperature was held for $15 \mathrm{~min}$. All peaks were identified by gas-chromatography/ mass-spectrometry using a Kratos MS80 RFA mass-spectrometer, interfaced to a Carlo-Erba 5160 chromatograph. Chromatographic conditions were as above, except that a $25 \mathrm{M} \mathrm{BP}-1$ (SGE) column was used. The instrument was operated in electron-impact mode at an ionization energy of $70 \mathrm{eV}$, trap current of $100 \mu \mathrm{A}$, and a scan rate of $0.3 \mathrm{~s}$ per decade of mass. FAB mass spectra were obtained with a Kratos MS80 RFA equipped with an Ion-Tech saddle field gun using xenon $(8 \mathrm{keV})$ as the bombarding gas. The accelerating voltage was $4 \mathrm{kV}$ and the magnet was scanned downwards from mass 1500 at $30 \mathrm{~s}$ per decade of mass. The polar lipid extracts ( $1 \mu 1$ samples) were applied 
to the stainless steel FAB target which had been previously coated with liquid matrix [dithiothreitol/diethylerythritol $(5: 1, v / v)$ containing $1 \%$ (v/v) 5-crown-15]. Scans were acquired under the control of the DS90 data system which had been previously calibrated with caesium iodide clusters over the mass range of interest.

\section{Results}

Strains $74 / 81$ and Corby grew well in ABCD broth which has been found suitable for the growth of $L$. pneumophila serogroup 1 (Knoxville 1), L. bozemanii and L. dumoffi in batch culture (Pine et al., 1986). However, growth of both strains was critically affected by the dissolved oxygen tension (DOT) of the culture. Preliminary chemostat experiments using several different levels of DOT indicated that maximal biomass concentration occurred at a DOT of $4 \%(\mathrm{v} / \mathrm{v})$ air saturation at $30^{\circ} \mathrm{C}$ [equivalent to $0.31\left(\mathrm{mg} \mathrm{O}_{2}\right)^{-1}$ ]. This is consistent with reports of oxygen toxicity in L. pneumophila (Locksley et al., 1982; Pine et al., 1986) Since the DOT is influenced by temperature, the oxygen concentration was maintained at $0.31 \mathrm{mg} \mathrm{1^{-1 }}$ during growth at $24^{\circ} \mathrm{C}$ and $37^{\circ} \mathrm{C}$ by adjusting the DOT to $3.6 \%(\mathrm{v} / \mathrm{v})$ and $4.5 \%(\mathrm{v} / \mathrm{v})$, respectively. To promote growth the medium was deoxygenated with nitrogen until the DOT decreased to $4 \%(\mathrm{v} / \mathrm{v})$, prior to inoculation. The DOT was kept low by restricting agitator speed until growth was established. Steady state growth, defined by a constant culture turbidity and cell yield [(g dry wt) $\left.\mathrm{l}^{-1}\right]$, was achieved within 10 generations.

\section{Nutrient utilization and limitation}

Analysis of the clarified culture supernatants of strain $74 / 81$ showed that although serine was the principal source of carbon and energy, it remained in excess during steady state growth at all temperatures (Table 1), in agreement with the findings of George et al. (1980) for batch culture of $L$. pneumophila using a similar medium. Metabolism of approximately $18.5 \mathrm{~mm}$-serine was accompanied by the production of approximately $15 \mathrm{mM}-$ ammonia. Increasing the growth temperature from $30^{\circ} \mathrm{C}$ to $37^{\circ} \mathrm{C}$ did not cause any significant change in the metabolism of serine; ammonia production, however, did increase. Lowering the growth temperature to $24^{\circ} \mathrm{C}$ slightly decreased serine utilization. Similar results were obtained with the clinical strain Corby (data not shown).

Only a few amino acids were completely depleted at $24^{\circ} \mathrm{C}$ but several more could not be detected in the culture supernatants at the higher growth temperatures. To ascertain whether any of these were actually growthlimiting, the concentrations of all the amino acids except serine were doubled in the incoming medium. The biomass concentration increased immediately and the
Table 1. Concentration of nutrients (mM) in unused $A B C D$ broth and in culture filtrate

L. pneumophila $74 / 81$ was grown in a chemostat at $D=0.08 \mathrm{~h}^{-1}$ with dissolved oxygen concentration of $0.31 \mathrm{mg} \mathrm{I}^{-1}$ and $\mathrm{pH} 6.9$, at the temperatures shown. Figures for unused broth are means of 11 samples, filtrate figures are means of three samples. Standard deviations were all less than $15 \%$ of the mean.

\begin{tabular}{|c|c|c|c|c|}
\hline \multirow[b]{2}{*}{ Nutrient } & \multirow{2}{*}{$\begin{array}{l}\text { Unused } \\
\text { medium }\end{array}$} & \multicolumn{3}{|c|}{$\begin{array}{c}\text { Culture filtrate } \\
\text { growth temperature }\left({ }^{\circ} \mathrm{C}\right)\end{array}$} \\
\hline & & 24 & 30 & 37 \\
\hline Iron* & 0.16 & $0 \cdot 16$ & $0 \cdot 16$ & $0 \cdot 16$ \\
\hline Potassium & $21 \cdot 85$ & $20 \cdot 46$ & $20 \cdot 89$ & $23 \cdot 38$ \\
\hline Zinc* & 0.08 & 0.08 & 0.08 & 0.08 \\
\hline Ammonium & $7 \cdot 30$ & $22 \cdot 25$ & 21.67 & $24 \cdot 00$ \\
\hline Phosphate & 1.64 & $1 \cdot 02$ & 0.99 & 1.07 \\
\hline Alanine & 0.93 & $1 \cdot 16$ & 0.60 & 0.60 \\
\hline Arginine & 0.54 & ND & ND & ND \\
\hline Asparagine & 0.66 & ND & ND & ND \\
\hline Aspartate & 0.62 & $0 \cdot 18$ & 0.25 & 0.08 \\
\hline Cysteine & 0.68 & $0 \cdot 26$ & $0 \cdot 32$ & 0.58 \\
\hline Cystine & $0 \cdot 12$ & 0.09 & 0.02 & 0.22 \\
\hline Glutamate & 0.59 & $0 \cdot 10$ & ND & 0.13 \\
\hline Glutamine & 0.54 & $0 \cdot 10$ & ND & ND \\
\hline Glycine & 0.97 & 0.88 & 0.74 & 0.86 \\
\hline Histidine & 0.36 & 0.06 & 0.05 & 0.05 \\
\hline Isoleucine & 0.70 & 0.06 & ND & 0.05 \\
\hline Leucine & 0.66 & 0.02 & ND & 0.04 \\
\hline Lysine & 0.44 & 0.06 & ND & ND \\
\hline Methionine & 0.59 & $0 \cdot 20$ & 0.06 & 0.04 \\
\hline Phenylalanine & 0.41 & ND & ND & ND \\
\hline Proline & 0.82 & ND & ND & ND \\
\hline Serine & $19 \cdot 03$ & 0.57 & $0 \cdot 24$ & 0.21 \\
\hline Threonine & 0.63 & 0.04 & ND & ND \\
\hline Tryptophan & $0 \cdot 28$ & $0 \cdot 20$ & $0 \cdot 22$ & 0.22 \\
\hline Tyrosine & $0 \cdot 12$ & ND & ND & ND \\
\hline Valine & 0.76 & 0.12 & ND & 0.08 \\
\hline
\end{tabular}

ND, not detected.

* Differences in the concentrations of iron and zinc between the medium and culture filtrate are most probably below the detection of the procedure used.

oxygen concentration decreased to zero, becoming growth-limiting, suggesting that growth in the original $\mathrm{ABCD}$ medium was limited by one of the amino acids but not serine. Supplementing the medium with a cocktail of several of the amino acids which were completely depleted at all three temperatures (asparagine, proline, phenylalanine, tyrosine and threonine; threonine was detectable at $24^{\circ} \mathrm{C}$, but at a very low level) similarly increased the yield and also resulted in oxygenlimited growth, indicating that one of these was growthlimiting. Doubling the concentration of tyrosine in the medium (to $0.56 \mathrm{mM}$ ) gave an increase in $\mathrm{OD}_{540}$ of 0.4 and an increase in dry weight of approximately $11 \%$, confirming tyrosine as the growth-limiting nutrient. These findings would also suggest that the other amino acids in the cocktail are not essential. Further supplementation of the medium with serine resulted in an 
Table 2. Growth characteristics of two different strains of L. pneumophila

Bacteria were grown in continuous culture at $D=0.08 \mathrm{~h}^{-1}, 0.31$ (mg dissolved oxygen) $1^{-1}$ and $\mathrm{pH} 6.9$, at the temperatures shown.

\begin{tabular}{|c|c|c|c|c|c|}
\hline \multirow[b]{3}{*}{ Characteristic } & \multicolumn{5}{|c|}{ Growth temperature $\left({ }^{\circ} \mathrm{C}\right)$} \\
\hline & \multicolumn{2}{|c|}{24} & \multirow{2}{*}{$\begin{array}{c}30 \\
74 / 81\end{array}$} & \multicolumn{2}{|c|}{37} \\
\hline & $74 / 81$ & Corby & & $74 / 81$ & Corby \\
\hline $\mathrm{OD}_{540}$ & $2 \cdot 7$ & 1.8 & 3.6 & $2 \cdot 8$ & $3 \cdot 4$ \\
\hline Biomass $\left[(\mathrm{g} \text { dry wt }) \mathrm{l}^{-1}\right]^{*}$ & 0.946 & 0.595 & 1.262 & 1.054 & $1 \cdot 317$ \\
\hline c.f.u. $\mathrm{ml}^{-1}\left(\times 10^{9}\right)^{\dagger}$ & $3.8 \pm 0.62$ & $1.5 \pm 0.39$ & $7.2 \pm 0.85$ & $2 \cdot 5 \pm 0 \cdot 50$ & $6.2 \pm 0.79$ \\
\hline$Y_{\text {serine }}\left(\mathrm{g} \mathrm{mol}^{-1}\right)$ & $51 \cdot 2$ & $45 \cdot 7$ & $67 \cdot 2$ & $56 \cdot 0$ & $70 \cdot 2$ \\
\hline$q_{\text {serine }}\left(\mathrm{mmol} \mathrm{g}^{-1} \mathrm{~h}^{-1}\right)$ & $1 \cdot 6$ & $1 \cdot 8$ & $1 \cdot 2$ & $1 \cdot 4$ & $1 \cdot 2$ \\
\hline PHB $(\%$ of cell dry wt) & $4 \cdot 3$ & ND & 2.9 & $1 \cdot 5$ & ND \\
\hline
\end{tabular}

additional increase in biomass concentration, indicating that serine was then limiting. The essential trace elements, including iron and zinc, remained in excess throughout the experiments.

\section{Growth yield}

The results of representative chemostat runs using each strain are given in Table 2. Similar results were produced on repeat experiments using fresh inocula. Three runs were carried out using strain $74 / 81$ as the inoculum and two with strain Corby. The culture $\mathrm{OD}_{540}$, biomass, molar growth yield for serine $\left(Y_{\text {serine }}\right)$ and viable count indicated that $74 / 81$ grew well at a temperature of $24^{\circ} \mathrm{C}$ (Table 2). This correlated with a high specific rate of serine metabolism $\left(q_{\text {serine }}\right)$. Raising the temperature from $24^{\circ} \mathrm{C}$ to $30^{\circ} \mathrm{C}$ caused an increase in the culture turbidity, biomass, $Y_{\text {serine }}$ and viable count, which was associated with a $25 \%$ decrease in $q_{\text {serine }}$ as the growth efficiency improved. The $Y_{\text {potassium }}$ and $Y_{\text {phosphate }}$ also increased by $93 \%$ and $27 \%$ respectively. This temperature appeared optimal for growth of strain $74 / 81$, since increasing the temperature to $37^{\circ} \mathrm{C}$ resulted in a lower $\mathrm{OD}_{540}$ and poorer recovery of viable bacteria. The biomass, $Y_{\text {serine }}$ and $q_{\text {serine }}$ however, were less affected, suggesting that the mean weight of individual cells had increased. Strain Corby exhibited a much greater increase in yield when grown at $37^{\circ} \mathrm{C}$ rather than at $24^{\circ} \mathrm{C}$, as indicated by an increase in cell dry weight of $121 \%$ and an increase of $54 \%$ in $Y_{\text {serine }}$ (Table 2).

\section{Morphology}

Changes in the growth temperature resulted in morphological differences (Figure 1). At $24^{\circ} \mathrm{C}$, short fine rods, approximately $1.3 \mu \mathrm{m} \times 0.25 \mu \mathrm{m}$ were observed, many of them bearing a single sub-polar flagellum $(3 \cdot 6-5 \mu \mathrm{m}$ long). Free flagella were also present, these having presumably been sheared off by the rapid agitation of the culture. No flagella were observed at either $30^{\circ} \mathrm{C}$ or $37^{\circ} \mathrm{C}$, either attached to the cells or free in the culture. The absence of flagella on cells grown at $30^{\circ} \mathrm{C}$ and $37^{\circ} \mathrm{C}$ may be due to the increase in shear force caused by the higher agitator speeds required to maintain the oxygen concentration at these temperatures (due to lower oxygen solubility and increased demand for oxygen resulting from the greater biomass concentrations at these temperatures), and failure to observe free flagella in the electron microscope preparations. Some of the cells appeared slightly elongated at $30^{\circ} \mathrm{C}(1.8 \mu \mathrm{m} \times 0.4 \mu \mathrm{m})$ and intracellular inclusions could be seen in the majority. The culture exhibited a high degree of pleomorphism at $37^{\circ} \mathrm{C}$ with long rods predominating. These were up to $8 \mu \mathrm{m}$ in length and intracellular inclusions of up to $0.5 \mu \mathrm{m}$ diameter were observed in a proportion of the cells. Although there are numerous examples of growth environment influencing cell morphology (e.g. Herbert, 1961; Brown \& Hough, 1965) it should be noted that a direct relationship between agitator speed and mean cell volume was reported by Wase et al. (1982).

The negatively-stained appearance of inclusion granules either remaining inside or released from the cell envelope of lysed bacteria suggested that they were indeed solid granules, and not vacuoles (Fig. 2). Discrete granules were also observed with a light microscope after staining the cells with the lipophilic stain Sudan Black. Chemical analysis of the bacteria confirmed the presence of the well-known microbial carbon storage compound polyhydroxybutyrate (PHB). PHB comprised $4.3 \%$ of the dry weight of cells grown at $24{ }^{\circ} \mathrm{C}$ but decreased to 

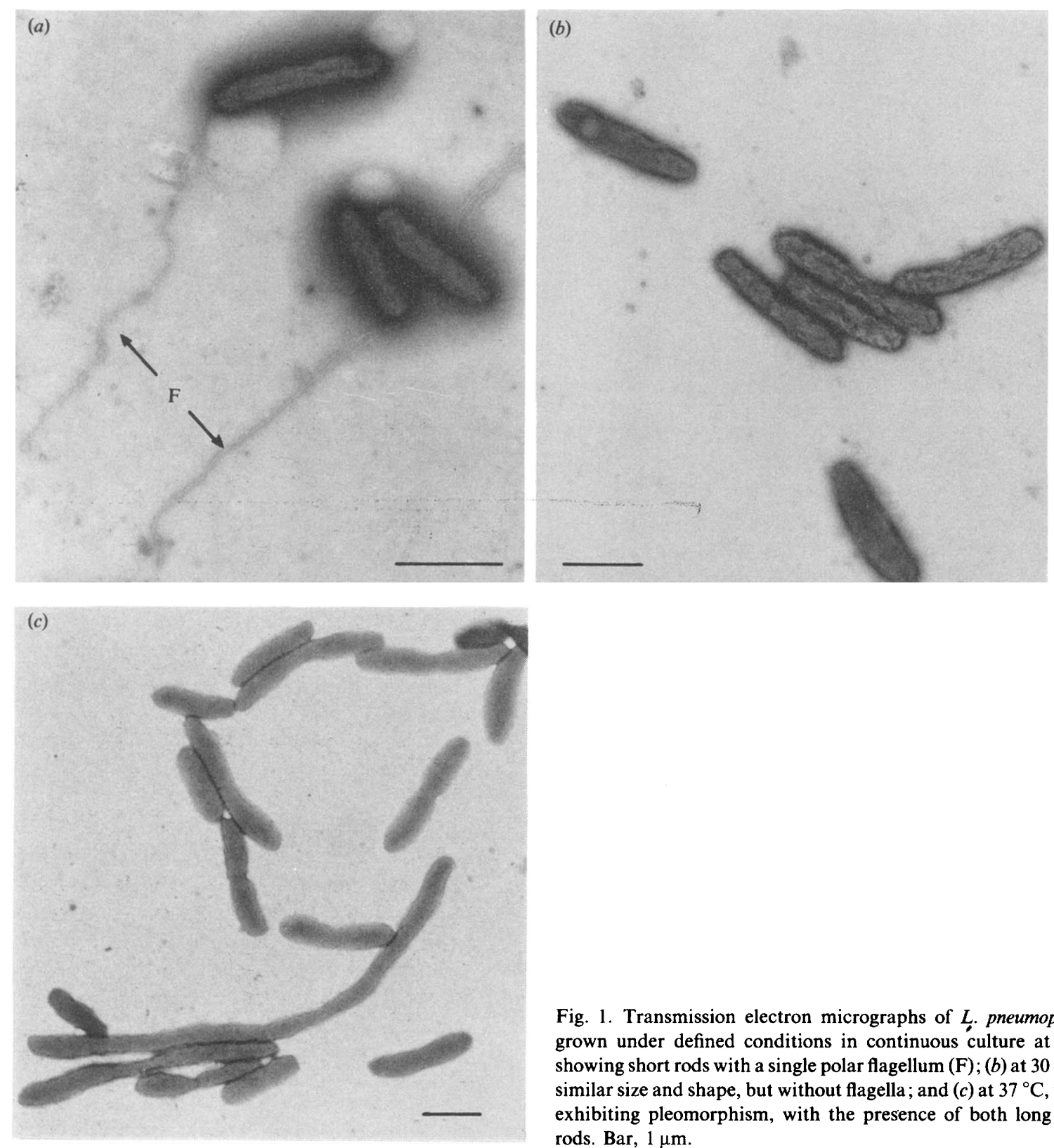

Fig. 1. Transmission electron micrographs of $L$. pneumophila $74 / 81$ grown under defined conditions in continuous culture at $(a) 24^{\circ} \mathrm{C}$, showing short rods with a single polar flagellum $(\mathrm{F}) ;(b)$ at $30^{\circ} \mathrm{C}$, cells of similar size and shape, but without flagella; and $(c)$ at $37^{\circ} \mathrm{C}$, the culture exhibiting pleomorphism, with the presence of both long and short rods. Bar, $1 \mu \mathrm{m}$.

$1.5 \%$ at $37^{\circ} \mathrm{C}$ (Table 2). The proportion of cells containing granules did not, however, correlate with the PHB content of the biomass, therefore other possibilities were investigated. Thin sections of bacteria were examined by electron microscopy after treatment with the polysaccharide-specific silver proteinate stain of Thiéry (1967). The intracellular granules did not take up the stain, which indicates that they are not composed of glycogen or other polysaccharides.

Extracellular material is frequently observed in Gramnegative bacteria, including $L$. pneumophila grown in complex media (Dennis, 1986) but none was observed in the present study.

Although the cultures were transiently brown-pigmented in the initial batch culture phase, no pigmentation was observed during continuous culture. However, when continuous cultures were pulsed with excess tyrosine brown, pigmentation was observed, probably due to melanin formation following tyrosinase activity.

\section{Membrane fatty acid content}

The fatty acid composition of $L$. pneumophila is unusual among Gram-negative bacteria because of the predominance of branched chain acids, of which 14-methyl pentadecanoic acid (i-16:0) was the most abundant 

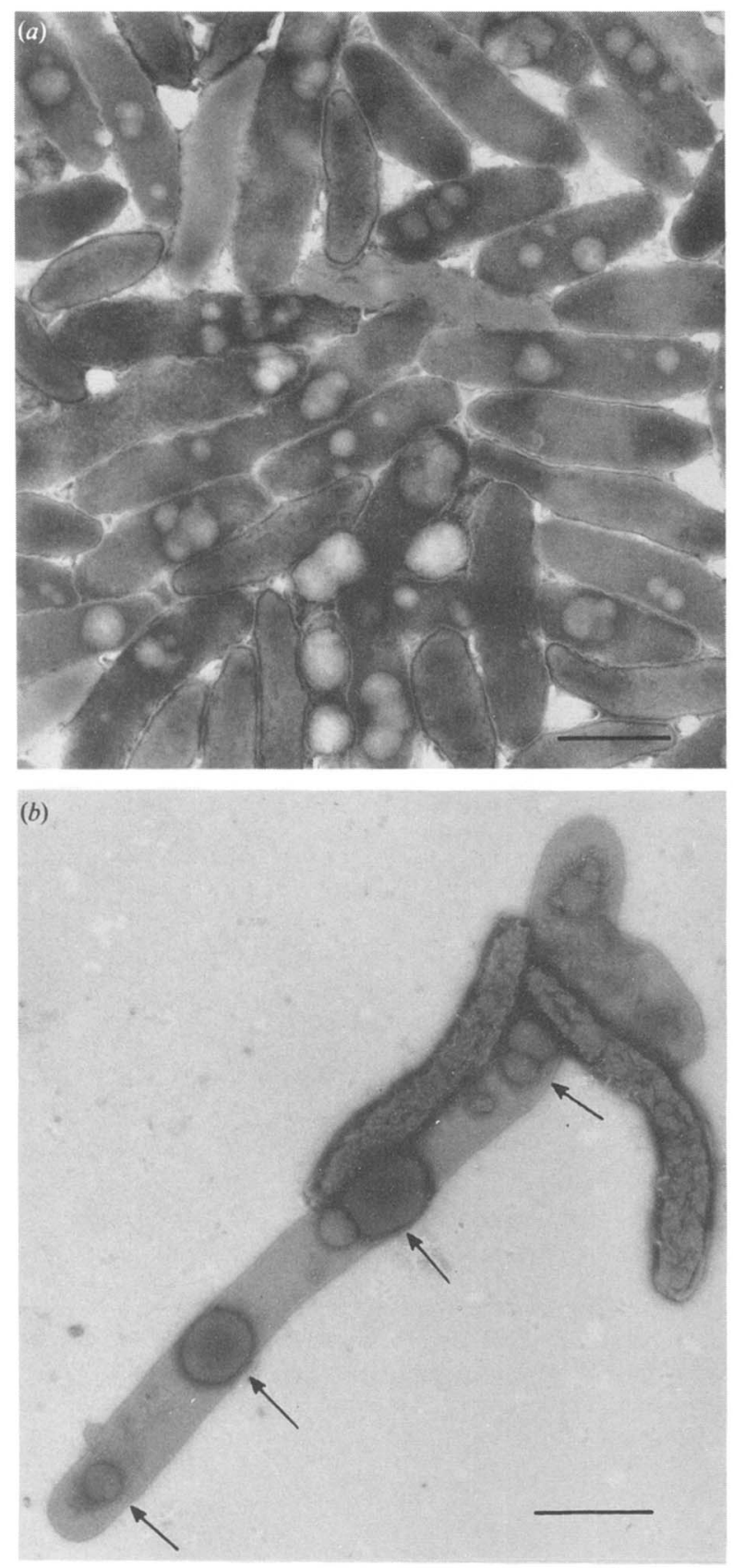

when the organism was grown on BCYE agar at $37^{\circ} \mathrm{C}$ (Moss et al., 1977). A similar fatty acid profile was obtained in continuous culture at $37^{\circ} \mathrm{C}$ using defined medium (Table 3). However, as the temperature of the culture was lowered, there was a progressive reduction in the relative proportion of saturated acids, particularly $\mathrm{i}-16: 0$ and $\mathrm{i}-14: 0$, and a corresponding increase in unsaturated acids so that at $24{ }^{\circ} \mathrm{C}$ the most abundant acid was 9-hexadecenoic acid, and the proportion of $\mathrm{i}-16: 0$ had fallen to less than $20 \%$ of the total (Table 3). The 9,10 methylenehexadecanoic acid (cyclopropane 17), a significant constituent of legionellae grown on BCYE agar (Moss et al., 1977) was barely detectable in bacteria grown at $37^{\circ} \mathrm{C}$ in continuous culture and was absent at $24^{\circ} \mathrm{C}$.

\section{Phospholipid analysis}

FAB-MS was used to record profiles of intact phospholipids at the various temperatures. Two representative spectra are shown in Fig. 3. Signals in the region $\mathrm{m} / \mathrm{z}$ 664-706 represent the protonated molecular ions of phosphatidylethanolamines and $N$-methylphosphatidylethanolamines, while those between $\mathrm{m} / \mathrm{z} 718$ and 748 correspond to phosphatidylcholines, all varying in their pattern of fatty acid substitution. The cluster of ions between 523 and 563 are fragments derived from the loss of the polar head group from phosphatidylethanolamines and phosphatidylglycerols, with charge retention on the glycerol backbone fragment.

Several differences are apparent between the $37^{\circ} \mathrm{C}$ and the $24^{\circ} \mathrm{C}$ samples. Firstly, as the temperature is reduced, the proportion of phospholipids containing an unsaturated fatty acid substituent is increased; thus the

\footnotetext{
Fig. 2. Transmission electron micrographs of $L$. pneumophila $74 / 81$ grown under defined conditions in continuous culture at various temperatures, showing the presence of intracellular granules. (a) A field showing cells grown at $30^{\circ} \mathrm{C}$, most cells have at least one granule, and (b) $37^{\circ} \mathrm{C}$, showing the cell envelope of long cell containing several granules. Bar, $1 \mu \mathrm{m}$.
}

Table 3. Influence of temperature on the membrane fatty acid composition (\%) of L. pneumophila grown in continuous culture

\begin{tabular}{crrrrrrrrrrr}
\hline & \multicolumn{10}{c}{ Fatty acid } \\
\cline { 2 - 11 } Temperature & $\mathrm{i} 14: 0$ & $\mathrm{a} 15: 0$ & $\mathrm{i} 16: 1$ & $\mathrm{i} 16: 0$ & $16: 1$ & $16: 0$ & $\mathrm{a} 17: 1$ & a17:0 & $17: 0$ & $18: 0$ \\
\hline $44^{\circ} \mathrm{C}$ & 3 & 5 & $<1$ & 36 & 12 & 12 & $<1$ & 19 & 3 & 9 \\
$37^{\circ} \mathrm{C}$ & 2 & 9 & 1 & 31 & 23 & 11 & $<1$ & 11 & 6 & 8 \\
$30^{\circ} \mathrm{C}$ & 1 & 7 & 2 & 32 & 30 & 10 & 1 & 6 & 2 & 6 \\
$24^{\circ} \mathrm{C}$ & $<1$ & 7 & 4 & 17 & 30 & 10 & 3 & 15 & 4 & 4 \\
\hline \hline
\end{tabular}



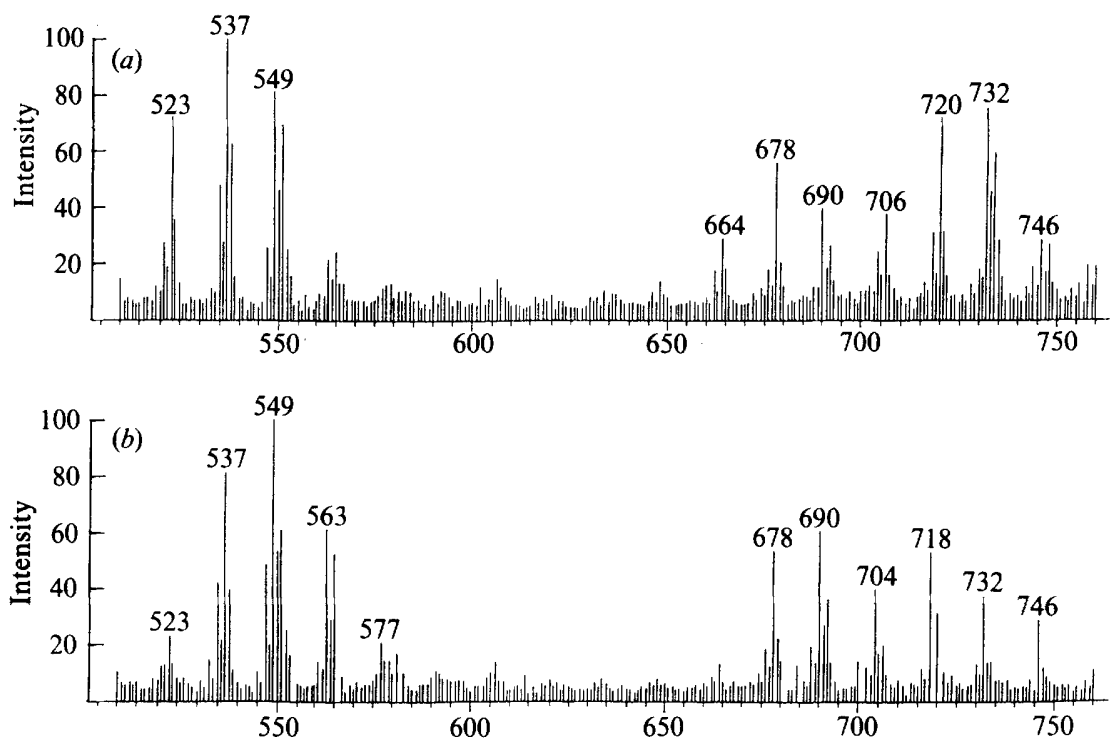

Fig. 3. Part of the positive ion FAB mass spectra of $L$. pneumophila strain $74 / 81$ grown under defined conditions in continuous culture at (a) $37^{\circ} \mathrm{C}$ and (b) $24^{\circ} \mathrm{C}$.

signals $m / z 690,704$ and 718 are significantly enhanced at low temperature. This tendency is particularly pronounced in the phosphatidylcholines, as the signals $m / z 734$ and 748 are virtually absent at $24^{\circ} \mathrm{C}$. In general, the unsaturated phospholipid species included only one double-bond-containing substituent. Digestion with phospholipase $\mathrm{A}_{2}$ followed by FAB-MS demonstrated that these were almost exclusively located on position 2 of the glycerol. The reduced synthesis of tetradecanoic acid at low temperature is reflected in the low intensity of $m / z 664$ at $24^{\circ} \mathrm{C}$, while the slightly increased production of ai17:0 at this temperature (Table 3) results in an enhancement of $m / z 678$. Finally, there appears to be an overall reduction of the relative proportion of phosphatidylcholines as the temperature is lowered.

\section{Discussion}

The use of a chemically defined medium in conjunction with continuous culture has permitted a detailed investigation of how the growth environment modulates the physiology and morphology of $L$. pneumophila. Serine provided the principal source of carbon, nitrogen and energy, and tyrosine proved to be the growth-limiting nutrient. Only $15 \mathrm{~mm}$-ammonia was produced from the $18.5 \mathrm{~mm}$-serine metabolized at $24^{\circ} \mathrm{C}$, so the remainder was presumably incorporated into biomass, since the deamination of serine should result in a stoichiometric production of ammonia.

This study, in common with others, has shown that temperature has a pronounced effect on the cellular morphology of L. pneumophila. Pine et al. (1979) used a similar medium supplemented with casein hydrolysate and, in batch culture, found coccobacillary L. pneumophila at $24^{\circ} \mathrm{C}$ which became pleomorphic above $30^{\circ} \mathrm{C}$. Later, Berg et al. (1985) observed pleomorphism at $37^{\circ} \mathrm{C}$ and $44^{\circ} \mathrm{C}$ in continuous culture using a complex yeast extract medium supplemented with starch and cysteine. However, neither study commented on the presence or absence of flagella. Dennis (1986) noted induction of flagella in continuous culture at low temperature, using a complex yeast extract medium, and recently Ott et al. (1991) showed that in two strains of L. pneumophila the proportion of cells bearing flagella decreased with increasing growth temperature. The motility provided by flagella confers obvious benefits on aquatic microorganisms; in vivo, however, flagella may not only be unnecessary, but may indeed have a detrimental effect on the survival of the bacteria due to their antigenicity.

Intracellular granules were discernible in electron micrographs and were observed by light microscopy after staining with the lipid stain Sudan Black. Although the presence of intracellular granules has not been commented on previously by physiologists and biochemists working with legionellae, such granules have been observed in vivo by microscopists. For example, Chandler $e t$ al. (1979) noted the presence of lipid granules in legionellae growing in alveolar macrophages at $37^{\circ} \mathrm{C}$. Similar observations were made for legionellae growing in yolk sac membranes (Rodgers, 1979), the protozoon Tetrahymena pyriformis (Fields et al., 1986) and the amoeba Acanthamoeba palestensis at $35^{\circ} \mathrm{C}$ (Anand et al., 1983). By contrast, few granules were observed in 
legionellae growing in Acanthamoeba polyphaga at a lower temperature of $30^{\circ} \mathrm{C}$ (Rowbotham, 1984). The apparent influence of temperature on granule formation was confirmed by the present study, in which maximum granule formation was noted at $30^{\circ} \mathrm{C}$, significantly fewer being observed at $37^{\circ} \mathrm{C}$ and very few at $24^{\circ} \mathrm{C}$. Since the abundance of granules did not correlate to the PHB content of the biomass, and the granules do not appear to be polysaccharide, their precise nature remains to be established. Chemical analysis confirmed that the cells contained the storage compound PHB (Mauchline \& Keevil, 1991; R. Wait, W. S. Mauchline, R. Araujo and C. W. Keevil, unpublished results). PHB comprised $4.3 \%$ of the cell dry weight when bacteria were grown at $24{ }^{\circ} \mathrm{C}$ and decreased to $1.5 \%$ when the growth temperature was increased to $37^{\circ} \mathrm{C}$. PHB synthesis was not completely abolished, probably because the bacteria were not carbon-limited, as serine remained in excess at all temperatures. At $24^{\circ} \mathrm{C}, L$. pneumophila exhibited the lowest effciency of biomass production for serine metabolized $\left(q_{\text {serine }}\right)$, however, the PHB content of the cells was maximal at this temperature, suggesting that the accumulation of this storage compound is favoured at lower temperatures.

The assumed pathway for PHB synthesis from amino acids such as serine is via pyruvate and acetyl CoA (Dawes \& Senior, 1973): tions in this study. They may therefore need alternative electron acceptors to recycle cofactors.

A previous study has indicated that there was no significant difference between the fatty acid profiles of L. pneumophila grown on BCYE agar or in continuous culture using complex yeast extract medium at comparable temperatures, except that the production of 9,10 methylene hexadecanoic acid (cyclopropane 17) was much reduced in the chemostat (Wait, 1988). Similar results were obtained in the present study using a defined medium, except that at $24^{\circ} \mathrm{C}$ the cyclopropane 17 acid is completely absent. In other micro-organisms (Halper \& Norton, 1975), including L. feeleii (Moss et al., 1983), it has been observed that cyclopropane acids accumulate as the culture ages, the rate of their synthesis being lowest in the exponential phase. Hence it is unsurprising that concentrations are low in cells grown in continuous culture, where the majority of cells are by definition in the exponential phase.

Bacteria can only grow if their cell membranes are in a largely fluid state; i.e. if the temperature is above the gel to liquid-crystalline transition temperature of their membrane lipids so as to ensure the maintenance of essential transport functions. Thermotolerant organisms, such as legionellae, thus require adaptive mechanisms to ensure that their membranes are fluid across a wide temperature range. Generally, such adaptive

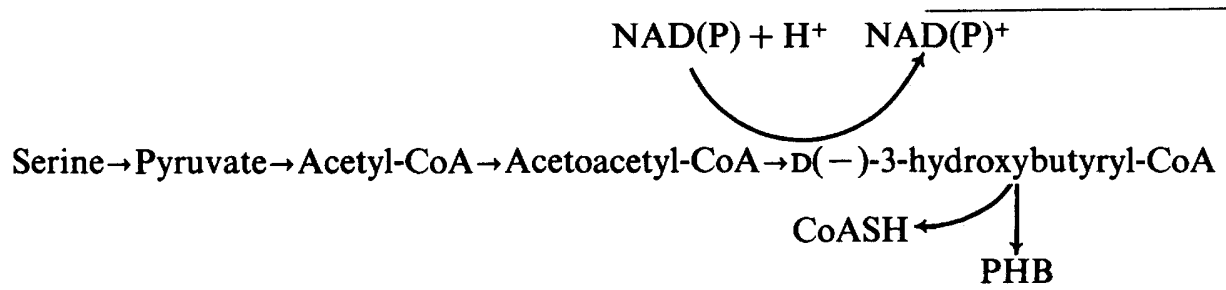

The synthesis of a carbon reserve such as PHB would provide an essential source of carbon and energy for survival in low-nutrient environments. Legionellae are able to metabolize exogenous 3-hydroxybutyric acid as a carbon source (Mauchline \& Keevil, 1991) suggesting that they are able to grow following hydrolysis of the intracellular PHB reserve. This would explain their ability to maintain their ATP content for many months with no additional nutrient source (West et al., 1989). It is also possible that PHB provides a carbon and energy supply for growth in macrophage and amoebae.

The PHB biosynthetic pathway also provides a mechanism to reoxidize $\mathrm{NAD}(\mathrm{P}) \mathrm{H}$ to $\mathrm{NAD}(\mathrm{P})$ to continue essential metabolic processes. Aerobes normally oxidize $\mathrm{NAD}(\mathrm{P}) \mathrm{H}$ via the respiratory chain with oxygen as the terminal electron acceptor. Legionellae, however, behave as microaerophiles (Hoffman et al., 1983; Locksley et al., 1982) and were inhibited by oxygen concentrations above $1 \mathrm{mg}^{-1}$ under the condi- strategies involve the synthesis of membrane constituents of lower melting point at reduced growth temperature. This can be achieved by switching fatty acids from saturated to unsaturated, from unbranched to branched, from iso- to ante-iso branched, by reducing acyl chain length, and by alteration of phospholipid type (Melchoir, 1982). The present data suggest that in $L$. pneumophila the major mechanism at work is increased production of unsaturated fatty acyl chains at low growth temperature. There is no evidence of any tendency towards acyl chain shortening. It is however significant that the reduction in saturated acid content is achieved almost entirely at the expense of straight chain and iso-branched acids, which have a significantly higher melting temperature than their ante-iso branched isomers (Rilfors et al., 1978). The alterations in phospholipid composition are less easy to interpret. The reduced content of phosphatidylcholines at low temperature seems surprising, as phosphatidylcholines have a $20^{\circ} \mathrm{C}$ lower melting temperature than 
phosphatidylethanolamines with identical acyl substituents (Chapman et al., 1967; Wilkinson \& Nagle, 1981). However, since this is due to packing effects and the greater ability of the ethanolamine head group to form inter-molecular hydrogen bonds, the effect is likely to be less pronounced in mixed phospholipids. It would seem likely that increasing the proportion of unsaturated substituents in phospholipids of all types has a greater effect on phase transition temperatures than alterations to the polar head group.

In conclusion, the data obtained on the growth yields of L. pneumophila, and on its nutrient utilization are proving useful in our continuing investigation of the influence of environmental parameters such as temperature and iron-limitation on the virulence of $L$. pneumophila.

We should like to thank Dr C. Davies and his department for providing chemical analyses of culture filtrates and media samples, and Mr M. Riches and his section for media preparation. We gratefully acknowledge the Medical Research Council of Great Britain (Project grant G8823698SB) for funding this work

\section{References}

Anand, C. M., Skinner, A. R., Malic, A. \& Kurtz, J. B. (1983). Interaction of $L$. pneumophila and a free living amoeba (Acanthamoeba palestinensis). Journal of Hygiene, Cambridge 91, 167-178.

BerG, J. D., Hoff, J. C., RoberTs, P. V. \& Matin, A. (1985). Growth of Legionella pneumophila in continuous culture. Applied and Environmental Microbiology 49, 1534-1537.

Bligh, E. G. \& DYeR, W. J. (1959). A rapid method of total lipid extraction and purification. Canadian Journal of Biochemistry and Physiology 37, 911-917.

Brown, C. M. \& Hough, J. S. (1965). Elongation of yeast cells in continuous culture. Nature, London 206, 676-678.

BuRDON, K. L. (1946). Fatty acid material in bacteria revealed by staining dried, fixed slide preparations. Journal of Bacteriology 52, 665.

Chandler, F. W., Blackmon, J. A., Hicklin, M. D., Cole, R. M. \& Callaway, C. S. (1979). Ultrastructure of the agent of Legionnaires' disease in the human lung. American Journal of Clinical Pathology 71, 43-50.

Chapman, D., Williams, R. M. \& Ladbrook, B. D. (1967). Physical studies of phospholipids. Chemistry and Physics of Lipids 1, 445-476.

DAWES, E. A. \& SENIOR, P. J. (1973). The role and regulation of energy reserve polymers in microorganisms. Advances in Microbial Physio$\log y 10,135-266$.

DENNIS, P. J. (1986). Environmental factors affecting the survival and the pathogenicity of Legionella pneumophila. $\mathrm{PhD}$ thesis, University of Warwick, UK.

Dennis, P. J., Taylor, J. A., Fitzgeorge, R. B., Barlett, C. L. R. \& BARROW, G. I. (1982). Legionella pneumophila in water plumbing systems. Lancet 1, 949-951.

Dennis, P. J., Green, I. \& Jones, B. P. C. (1984). A note on the temperature tolerance of Legionella. Journal of Applied Bacteriology 56, 349-350.

EDELSTEIN, P. H. (1981). Improved semi-selective medium for isolation of Legionella pneumophila from contaminated clinical and environmental specimens. Journal of Clinical Microbiology 14, 298-303.

Feeley, J. C., Gorman, G. W., Weaver, R. E., Mackel, D. C. \& SMITH, H. W. (1978). Primary isolation media for Legionnaires' disease bacterium. Journal of Clinical Microbiology 8, 320-325.
Fields, B. S., Barbaree, J. M., Shotts, E. B., Feeley, J. C., Morill, W. E., SANDEN, G. N. \& Dykstra, M. J. (1986). Comparison of guinea pig and protozoan models for determining virulence of Legionella species. Infection and Immunity 53, 553-559.

FINDLAY, R. H. \& WHITE, D. C. (1983). Polymeric beta-hydroxyalkanoates from environmental samples and Bacillus megaterium. Applied and Environmental Microbiology 45, 71-78.

Fliermans C. B., Cherry, W. B., OrRison, L. H., Smith, S. J., Tison, D. L. \& POPE, D. H. (1981). Ecological distribution of Legionella pneumophila. Applied and Environmental Microbiology 41, 9-16.

George, J. R., Pine, L., Reeves, M. W. \& Harrell, W. K. (1980). Amino acid requirements of Legionella pneumophila. Journal of Clinical Microbiology 11, 286-291.

HALPER, L. A. \& NORTON, S. J. (1975). Regulation of cyclopropane fatty acid biosynthesis by variation in enzyme activities. Biochemical and Biophysical Research Communications 62, 683-688.

HERBERT, D. (1961). The chemical composition of micro-organisms as a function of their environment. Symposia of the Society for General Microbiology 11, 391-416.

Herbert, D., Elsworth, R. \& Telling, R. C. (1956). The continuous culture of bacteria: a theoretical and experimental study. Journal of General Microbiology 14, 601-622.

Hoffman, P. (1984). Bacterial physiology. In Proceedings of the 2nd International Symposium on Legionella, pp. 61-67. Edited by C. Thornsberry, A. Balows, J. C. Feeley \& W. Jakubowski. Washington, DC: American Society for Microbiology.

Keevil, C. W., Glenister, D. A., Salamon, K. E., Dennis, P. J. \& WEST, A. A. (1988). A continuous culture biofilm model for the study of medical and industrial corrosion. In Biofilms, pp. 48-62. Edited by L. H. G. Morton \& A. H. L. Chamberlain. Kew: Biodeterioration Society Press.

LOCKSLEY, R. M., JACOBS, R. F., Wilson, C. B., Weaver, W. M. \& KLEBANOFF, S. J. (1982). Susceptibility of Legionella pneumophila to oxygen-dependent microbiocidal systems. Journal of Immunology 129, 2192-2197.

Mauchline, W. S. \& KeEvil, C. W. (1991). Development of the BIOLOG subsirate utilisation system for identification of Legionella spp. Applied and Environmental Microbiology 57, 3345-3349.

MeLCHOIR, D. L. (1982). Lipid phase transitions and regulation of membrane fluidity in prokaryotes. Current Topics in Membranes and Transport 17, 263-316.

Monod, J. (1950). La technique de culture continue; théorie et applications. Annales de l'Institut Pasteur 79, 390-410.

Moss, C. W., Weaver, R. E., Dees, S. B. \& Cherry, W. B. (1977). Cellular fatty acid compositions of isolates from Legionnaires' disease. Journal of Clinical Microbiology 6, 140-143.

Moss, C. W., BibB, W. F., KarR, D. E., Guerrant, G. O. \& Lambert, M. A. (1983). Cellular fatty acid composition and ubiquinone content of Legionella feeleii sp. nov. Journal of Clinical Microbiology 18, 917-919.

Novick, A. \& SzIlard, L. (1950). Experiments with the Chemostat on spontaneous mutations of bacteria. Proceedings of the National Academy of Sciences of the United States of America 36, 708-719.

Ott, M., Messner, P., Heesemann, J., Marre, R. \& Hacker, J. (1991). Temperature-dependent expression of flagella in Legionella. Journal of General Microbiology 137, 1955-1961.

Pine, L., George, J. R., Reeves, M. W. \& Harrell, W. K. (1979). Development of a chemically defined medium for growth of Legionella pneumophila. Journal of Clinical Microbiology 9, 615626.

Pine, L., Hoffman, P. S., Malcom G. S., Benson, R. F. \& Franzus, M. J. (1966) Role of keto acids and reduced oxygen scavenging enzymes in the growth of Legionella species. Journal of Clinical Microbiology 23, 33-42.

Rilfors, L., Wieslander, A. \& StaHL, S. (1978). Lipid and protein composition of membranes of Bacillus megaterium variants in the temperature range $5-70^{\circ} \mathrm{C}$. Journal of Bacteriology 135, 1043-1052.

Ristroph, J. D., Hedlund, K. W. \& GoWDA, S. (1981). Chemically defined medium for Legionella pneumophila growth. Journal of Clinical Microbiology 13, 115-119.

RODGERS, F. G. (1979). Ultrastructure of Legionella pneumophila. Journal of Clinical Pathology 32, 1195-1202. 
Rodgers F. G., Greaves, P. W., Macrae, A. D. \& Lewis, M. J. (1980). Electron microscopy evidence of flagella and pili on Legionella pneumophila. Journal of Clinical Pathology 33, 11841188.

Rowbotham, T. C. (1980) Preliminary report on the pathogenicity of Legionella pneumophila for freshwater and soil amoebae. Journal of Clinical Pathology 33, 1179-1183.

Rowвотнам, T. C. (1984) Legionellae and amoebae. In Proceedings of the 2nd International Symposium on Legionellae, pp. 325-327. Edited by C. Thornsberry, A. Balows, J. C. Feeley \& W. Jakubowski. Washington DC: American Society of Microbiology.

SlePECKY, R. A. \& LAW, J. H. (1960). A rapid spectrophotometric assay of alpha, beta-unsaturated acids and beta-hydroxy acids. Analytical Chemistry 32, 1697-1699.

TESH, M. J. \& MiLleR, R. D. (1981). Amino acids requirements for Legionella pneumophila growth. Journal of Clinical Microbiology 13, 865-869.

THIÉRY, J. P. (1967). Role de l'appareil de golgi dans la synthèse des mucopolysaccharides étude cytochimique. Journal de Microscopie (Paris) 8, 689-708.
Wadowsky, R. M., Wolford, R., McNamara, A. M. \& Yee, R. B. (1986). Effect of temperature, $\mathrm{pH}$ and oxygen level on the multiplication of naturally occurring Legionella pneumophila in potable water. Applied and Environmental Microbiology 49, 11971205.

WAIT, R. (1988). Confirmation of the identity of legionellae by whole cell fatty-acid and isoprenoid quinone profiles. In $A$ Laboratory Manual for Legionella, pp. 69-102. Edited by T. G. Harrison and A. G. Taylor. Chichester: John Wiley and Sons.

Wase, D. A. J., Nesaratam, S. T. \& Blakebrough, N. (1982). Variation of cell wall strength in Klebsiella pneumoniae NCTC 418 with change in agitation speed in a chemostat system. Journal of Chemical Technology and Biotechnology 32, 553-555.

West, A. A., Araujo, R., Dennis, P. J. L., Lee, J. V. \& Keevil, C. W. (1989). Chemostat models of Legionella pneumophila. In Airborne Deteriogens and Pathogens, pp. 107-116. Edited by B. Flannigan. Kew: Biodeterioration Society Press.

WILKInson, D. A. \& NAGLE, J. F. (1981). Dilatometry and calorimetry of saturated phosphatidylethanolamine. Biochemistry 20, 187192. 